\title{
UM NOVO FUNDEF? AS IDÉIAS DE ANÍSIO TEIXEIRA
}

\author{
Nelson Cardoso Amaral*
}

\begin{abstract}
RESU M 0: 0 professor Anísio Teixeira, na década de 1960, preocupado com o financiamento da educação, apresentou uma proposta de como definir e implantar um fundo que garantisse recursos permanentes parao ensino primário. Em seusaspectosmetodológicos, o Fundo deM anutenção eD esenvolvimento do Ensino Fundamental edeVal orização do M agistério (Fundef), criado pelo G overno, assemelha-se à proposta apresentada por A nísio Teixeira. Existem, entretanto, diferen çasim portantes efundamentais, pelo fato do professor Anísio definir o volume total de recursos a partir do estabelecimento do salário dos docentes. N esseestudo apresentam-seas semelhanças ediferenças entreos dois fundose real iza-se umasimulação do quesepoderiachamar "U m novo Fundef", baseado nasidéias deAnísio Teixeira. Como resultado, obtém-se valores perfeitamente viáveis para serem financiados por uma economia com adimensão da economia brasileira, assim como ocorreu no estudo apresentado por Anísio Teixeirano livro Educaçãoéum direito.
\end{abstract}

Palavras chave: Financiamento; Ensino fundamental; Fundo; Fundef.

0 professor Anísio Teixeira, em seu artigo "Bases preliminares para o plano de educação referente ao Fundo $\mathrm{N}$ acional de Ensino Primário" (1962) e no livro "Educação é um direito" (1968), apresenta um modelo para o financiamento do ensino primário vigente à época, e que, em seus aspectos metodológicos, assemelha-se ao Fundo de M anutenção e D esenvolvimento do Ensino Fundamental e de Valorização do M agistério (Fundef), instituído pela Emenda Constitucional no 14 de 12 de setembro de 1996.

A Constituição de 1946, então vigente, estabelecia "que a educação é direito de todos; que 0 ensino primário é obrigatório; que 0 ensino primário oficial é gratuito para todos e o ensino ulterior ao primário sêlo-á

* Professor do Instituto de Física da U niversidade Federal de Goiás (UFG) e doutorando em Educação na U niversidade M etodista de Piracicaba (U nimep). E-mail: izamaral @cultura.com.br 
para quantos provarem falta ou insuficiência de recursos" (1968, p. 51). Diante dessas condições, Anísio Teixeira discutia como implementá-las no cotidiano do País, financiando adequadamente a educação obrigatória de toda a população, e defendia a tese de que a Constituição, ao estabelecer percentuais mínimos da receita de impostos a serem aplicados em educação - 10\% para a União e 20\% para os estados e municípios -, "teve em vista prover para que não faltassem recursos destinados ao cumprimento da obrigação do Estado..." (Teixeira, 1968, p. 51).

Esses recursos, na visão de Anísio Teixeira, deveriam ser utilizados de forma solidária entre a U nião, estados e municípios, pois assim também estabelecia o texto constitucional.

As idéias apresentadas por Anísio Teixeira, entretanto, possuem diferenças nítidas em relação ao Fundef. Este possui, como principal objetivo, redistribuir entre municípios de um estado da federação os recursos já existentes para a educação fundamental, a partir da préfixação de um custo médio anual, nacional, do aluno. 0 Fundef prevê 0 aporte de recursos federais para aqueles Estados que não conseguirem, com seus próprios recursos, atingir esse custo médio nacional. As idéias de Anísio vão além: há uma efetiva preocupação com a qualidade do trabalho docente, expresso pela definição de um salário para o professor, e apresentam uma engenhosa articulação permanente entre as três esferas do poder público.

Apresentamos, neste estudo, em primeiro lugar, um resumo das idéias de Anísio Teixeira e, em seguida, uma explicitação dos principais pontos na definição do Fundef e, finalmente, faremos um resgate das idéias de Anísio para apresentarmos o que se poderia chamar um novo Fundef, analisando o volume de recursos envolvidos nesse contexto, comparando-o com recursos aplicados por outros países.

\section{Asidéias de Anísio Teixeira}

D iscutindo como financiar o ensino primário para todos, Anísio Teixeira expressa sua preocupação com a desigualdade econômica e com a "desigualdade cultural reinantes entre os municípios, que levariam à formação desigual dos alunos, conforme o local em que vivessem" (idem, p. 57). A diminuição dessa desigualdade poderia ser amenizada com a fixação de um "custo-padrão" da educação que deveria ser financiado "com os recursos dos três poderes públicos, União, Estados e M unicípios" (idem).

Para calcular o custo-padrão da chamada escola primária, Anísio Teixeira toma como base 0 salário do professor. $\mathrm{N}$ a definição dessa retri- 
buição ao trabalho docente a sua preocupação foi a de contar com profissionais "capazes e preparados" (idem, p. 58), o que ocorreria com um salário não inferior a 1,5 salário mínimo regional (1,5 x S.M .) - vigente à época - para uma carga de trabalho diário de 6 horas.

Do custo total da escola, Anísio Teixeira supôs que as despesas se distribuiriam da seguinte forma (1968, p. 58): $55 \%$ para o pagamento dos salários dos professores, 7\% para administração e serviços, 13\% para a biblioteca e material de ensino, 15\% para assistência, alimentação e saúde e $10 \%$ para prédios e equipamentos. Portanto, $45 \%$ do custo total da escola se originariam das despesas não vinculadas ao pagamento dos professores.

Considerando que a cada professor corresponderia uma classe de 35 alunos, Anísio calculou a despesa com a escola, por aluno, ao ano. Para isso, bastou calcular quanto cada professor receberia em 12 meses, ou seja, 1,5 x S.M. x 12 e dividir por 35 (alunos), o que resultou em $0,5143 \times$ S.M . Como este valor significa $55 \%$ do custo total do aluno, uma evolução para chegar a $100 \%$ resulta em 0,9351 x S.M. para 0 custo por aluno, ao ano. Ele chama atenção para os demais ônus das despesas de pessoal (Teixeira, 1962, p. 5), de responsabilidade do empregador público, o que nos leva a incorporar $14 \%$ a mais nesse valor, resultando, portanto, 1,0660 × S.M. para o custo por aluno, ao ano.

A partir dessa definição, para se obter a despesa com o ensino primário por estado, ao ano, é necessário apenas multiplicar o número total de alunos desse estado por 1,0660 x S.M . e, consequentemente, pode-se encontrar o montante de recursos para atender a todos os estudantes do País.

Para financiar esse total de estudantes, Anísio Teixeira definiu quotas-partes dos municípios, dos estados e da União. Caso as quotaspartes municipais e estaduais não fossem suficientes para completar 0 custo por aluno, ao ano (1,0660 x S.M .), a U nião entraria com a quotafederal, "correspondente ao que faltar" (1968, p. 61).

Após simular a sua modelagem, utilizando os dados da época, Anísio Teixeira observa:

Cumprenão esquecer queestamos apenas procurando ilustrar o nosso plano e não descer aos detalhes exatos de execução. Salientemos, entretanto, que a importância acima ser gasta com educação obrigatória, representaria da renda nacional de Cr\$18.867.300 milhões (1964), cerca de $\%$, o que pode ser considerado plenamentecompatível com a nossa situação econômica. O sEs- 
tados U nidos despendiam em 1958 3\% da renda nacional com a educação e 2,7\% com a educação obrigatória. H oje, esta porcentagem émaisalta.

0 autor apresenta, ainda, a proposta de constituir-se conselhos de educação de composição leiga, "com um alto grau de autonomia administrativa" (idem, p. 67). Os recursos financeiros seriam gerenciados por esses conselhos" sob a forma de fundos de educação - nacional, estaduais e municipais" (idem).

Anísio Teixeira, ao defender as suas idéias, diz que: "quando secre tário da educação do Estado da Bahia, entre 1947 e 1950" apresentou modelagem semelhante para aquele estado e o detal ha no Apêndice do livro em discussão, com o título: "Autonomia dos serviços de educação e cultura no Estado da Bahia" (1968, p. 105-165).

\section{O Fundef}

O Fundo de $M$ anutenção e D esenvolvimento do Ensino Fundamental e de Valorização do M agistério (Fundef), instituído pela Emenda Constitucional $n=14$, de 12 de setembro de 1996, e regulamentado pela Lei no 9.424, de 24 de dezembro de 1996, e pelo D ecreto 2264, de 27 de junho de 1997, compõe-se dos seguintes recursos: 15\% do Fundo de Participação dos Estados e do D istrito Federal (FPE), do Fundo de Participação dos M unicípios (FPM ), do Imposto sobre operações relativas à circulação de mercadorias e sobre prestações de serviços de transportes interestadual e intermunicipal e de comunicação (ICM S), do Imposto sobre Produtos Industrializados, proporcional às exportações (IPI-Exp) e do ressarcimento pela D esoneração de Exportações, de que trata a Lei Complementar no 87/96 (Lei Kandir). Esses recursos devem ser gastos exclusivamente com o Ensino Fundamental. Ele é constituído em cada estado e o efeito provocado pela sua constituição é o de redistribuir recursos dentro do próprio estado. O u seja, retira os recursos de alguns municípios e os remete para outros, de tal modo que uniformiza, em todo o estado, o valor gasto por estudante do ensino fundamental. Q uando esse valor não atinge um limite, que em 1998 foi de $R \$ 315,00$, o Governo Federal faz uma suplementação de recursos. A normatização do Fundef estabelece ainda que, no mínimo, 60\% dos recursos do fundo devem ser gastos com o pagamento dos profissionais da educação - professores e servidores - e os restantes $40 \%$ devem se dirigir para a manutenção e desenvolvimento do ensino.

Existe uma polêmica quanto ao valor mínimo anual por aluno. 0 valor de $\mathrm{R} \$ 315,00$ vem sendo questionado pelos secretários estaduais 
de educação e por diversos estudiosos do tema (M onlevade $\&$ Ferreira, 1997; D avies, 1998). A Lei no 9424 (1996) afirma, em seu Art. 6o, que o valor mínimo anual por aluno, ressalvado o primeiro ano da sua vigência em que esse valor será de $R \$ 300,00$, "será fixado por ato do Presidente da República e nunca será inferior à razão entre a previsão da receita total para o fundo e a matrícula total do ensino fundamental no ano anterior, acrescida do total estimado de novas matrículas...".

No livro 0 Fundef e seus pecados capitais (M onlevade \& Ferreira, 1997) seus autores detalham uma análise para 1998, quando afirmam que o M inistério da Fazenda projetava para 1998 uma arrecadação global do fundo de $R \$ 13.312 .110 .000,00$ e estimava o número de estudantes em 31.464.215, o que resulta um valor mínimo de $R \$ 423,07$. Procede, portanto, o questionamento de secretários e estudiosos, quando o $\mathrm{G}$ overno Federal divulgou o valor de $\mathrm{R} \$ 315,00$, deixando de cumprir a Lei $\mathrm{n}$ 9424 elaborada por ele próprio e encaminhada para aprovação pelo Congresso $\mathrm{N}$ acional.

A legislação prevê a existência, no âmbito de cada estado e de cada município, a instalação de um Conselho de Acompanhamento e Controle Social do Fundef, encarregado de acompanhar/fiscalizar a repartição, a transferência e a aplicação dos recursos. A esses conselhos incumbe, ainda, a supervisão do censo escolar anual. É a partir das informações do censo escolar que se obtém o quantitativo de estudantes matriculados no ensino fundamental, para se obter o montante de recursos a ser recebido pelos municípios e pelo estado.

0 Fundef é de definição transitória e o tempo de sua existência está limitado a 10 de janeiro de 2007, o que poderá significar imensos transtornos para os municípios que receberem complementação de recursos.

\section{Um novo Fundef baseado nas idéias de Anísio Teixeira}

Como seria um novo Fundef, adotando-se as premissas apresentadas por Anísio Teixeira? A primeira discussão que se nos apresenta é o valor do salário do professor. Se quisermos adotar 1,5 x S.M . como foi estabelecido, precisamos realizar uma análise do valor do salário mínimo no período de 1964 aos dias de hoje e verificar o seu valor relativo no ano de 1964, estendendo-o para os dias atuais.

Podemos fazer isso tomando como base o estudo do Dieese (2000) "Salário M ínimo: pouca comemoração para o 1ำ de maio". A Tabela 1, extraída deste estudo, mostra a evolução do salário mínimo real e do PIB 
per capita mensal, a partir de 1964, ano em que Anísio Teixeira explicitou os seus cálculos.

Tabela 1

Evolução do salário mínimo real eo PIB per capita mensal

\begin{tabular}{|c|c|c|c|}
\hline Ano & $\begin{array}{c}\text { PIB per capita mensal } \\
(\mathbf{R} \$)\end{array}$ & $\begin{array}{c}\text { Valor do Salário Mínimo } \\
\text { (R\$) }\end{array}$ & $\begin{array}{c}\% \text { do PIB per capita } \\
\text { mensal }\end{array}$ \\
\hline 1964 & 211,36 & 195,49 & 92,49 \\
\hline 1965 & 210,97 & 188,16 & 89,19 \\
\hline 1966 & 212,76 & 161,76 & 76,03 \\
\hline 1967 & 216,89 & 155,99 & 71,92 \\
\hline 1968 & 234,36 & 164,97 & 70,39 \\
\hline 1969 & 250,40 & 169,60 & 67,73 \\
\hline 1970 & 264,83 & 182,55 & 68,93 \\
\hline 1971 & 287,79 & 189,83 & 65,96 \\
\hline 1972 & 314,29 & 203,60 & 64,78 \\
\hline 1973 & 349,62 & 207,53 & 59,36 \\
\hline 1974 & 368,91 & 200,98 & 54,48 \\
\hline 1975 & 378,56 & 215,44 & 56,91 \\
\hline 1976 & 407,37 & 230,33 & 56,54 \\
\hline 1977 & 417,15 & 245,78 & 58,92 \\
\hline 1978 & 427,21 & 259,32 & 60,70 \\
\hline 1979 & 445,01 & 272,75 & 61,29 \\
\hline 1980 & 476,12 & 294,15 & 61,78 \\
\hline 1981 & 445,96 & 282,47 & 63,34 \\
\hline 1982 & 439,98 & 290,47 & 66,02 \\
\hline 1983 & 417,97 & 234,48 & 56,10 \\
\hline 1984 & 431,28 & 224,44 & 52,04 \\
\hline 1985 & 455,61 & 242,57 & 53,24 \\
\hline 1986 & 480,06 & 241,76 & 50,36 \\
\hline 1987 & 487,54 & 177,03 & 36,31 \\
\hline 1988 & 478,30 & 182,81 & 38,22 \\
\hline 1989 & 484,82 & 197,32 & 40,70 \\
\hline 1990 & 455,61 & 132,54 & 29,09 \\
\hline 1991 & 449,35 & 136,51 & 30,38 \\
\hline 1992 & 439,03 & 114,46 & 26,07 \\
\hline 1993 & 450,44 & 132,29 & 29,37 \\
\hline 1994 & 469,06 & 116,28 & 24,79 \\
\hline 1995 & 482,08 & 118,25 & 24,53 \\
\hline 1996 & 486,91 & 121,34 & 24,92 \\
\hline $1997 *$ & 498,49 & 126,22 & 25,32 \\
\hline $1998 *$ & 498,49 & 132,35 & 26,55 \\
\hline
\end{tabular}

Fonte: Dieese/IBGE. Elaboração das colunas 1, 2 e 3, do Dieese.

* PIB estimado. 
Apesar do crescimento do PIB per capita mensal de 1964 aos nossos dias, de $R \$ 211,36$ para $R \$ 498,49$, o salário mínimo caiu de $92,49 \%$ para $26,55 \%$ do PIB per capita mensal. Então, se quisermos examinar a existência de um novo Fundef, baseado nas idéias de Anísio Teixeira, teremos que trabalhar com um salário mínimo compatível com o crescimento econômico do País e colocando, como ele defendia, uma alta prioridade nacional para o financiamento da educação. Consideraremos, então, para o "salário mínimo" o valor de $\mathrm{R} \$ 461,00$, retomando o seu valor em relação ao PIB per capita mensal de 1964, ou seja, 92,49\% desse valor. Teremos, então, para o custo anual do aluno o valor de $\mathrm{R} \$$ 491,43, obtido a partir da expressão 1,0660 x S.M .

0 censo escolar de 1998 registrou 32.380.024 (M EC, 1999) estudantes matriculados no ensino fundamental. 0 volume total de recursos a ser aplicado no ensino fundamental, conforme proposto por Anísio Teixeira, poderá, então, ser estimado. 0 valor total de recursos dos estados e municípios aplicados em educação fundamental foi, em 1998, de R\$12.787.300.000,00 (M EC, 1999, p. 6) e a complementação da U nião foi de R \$524.200.000,00 (idem) - repassados aos estados do Pará, M aranhão, Piauí, Ceará, Paraíba, Pernambuco, Alagoas e Bahia. Se o valor mínimo anual, por aluno, fosse de $R \$ 491,43$, como estabelecido anteriormente, resultaria em uma complementação da U nião de $\mathrm{R} \$ 3.714 .400 .000,00$, conforme está detalhado na Tabela 2, o que beneficiaria, agora, os estados do Pará, Rondônia, Tocantins, Alagoas, Bahia, Ceará, M aranhão, Paraíba, Pernambuco, Piauí, Rio Grande do N orte, Sergipe, Goiás, M ato Grosso do Sul, M ato Grosso, Distrito Federal, M inas Gerais e Paraná.

Resultariam, portanto, $\mathrm{R} \$ 16.501 .700 .000,00$ como recursos a serem aplicados no ensino fundamental. Tomando emprestadas as palavras de Anísio Teixeira citadas anteriormente, podemos afirmar que a importância acima representaria do PIB nacional de 1998 - R\$913.735. 044.000,00 (I pea, 2000) - cerca de 1,81\%, o que pode ser considerado plenamente compatível com a nossa situação econômica. Em 1964, Anísio Teixeira obteve $2 \%$ e comparou esse resultado com o dos Estados Unidos, que em 1958 já aplicava 2,7\% do PIB norte-americano no ensino obrigatório.

\section{C omparação com os recursos aplicados por outros países.}

Para analisar como se compara esse percentual de 1,81\%, que seriam os gastos do novo Fundef com o percentual gastos por outros 
países, faremos uma comparação com países selecionados da América Latina e países de outros continentes. A seleção de países se deu, primordialmente, pela inexistência de dados em fontes internacionais como a Unesco e o Banco M undial para alguns países, inclusive o Brasil.

Tabela 2

Complementação daU nião: Valor mínimo anual $=\mathrm{R} \$ 491,43$

\begin{tabular}{|c|c|c|c|c|}
\hline $\begin{array}{l}\text { Unidade da } \\
\text { Federação }\end{array}$ & $\begin{array}{l}\text { Matrículas no } \\
\text { Ensino } \\
\text { Fundamental } \\
\text { Público (1998) } \\
\end{array}$ & $\begin{array}{c}\text { Valor } \\
\text { Anual por } \\
\text { Aluno* } \\
(\mathbf{R} \$) \\
\end{array}$ & $\begin{array}{c}\text { Complementação } \\
\text { Anual da União } \\
\text { para R\$ 491,43 } \\
(1998) \\
\end{array}$ & $\begin{array}{c}\text { Total da } \\
\text { Complementação } \\
\text { da União } \\
\text { (R\$ Milhões) } \\
\end{array}$ \\
\hline Acre & 132.417 & 555,11 & - & - \\
\hline Amazonas & 600.440 & 509,72 & - & - \\
\hline Amapá & 115.630 & 664,72 & - & - \\
\hline Pará & 1.518 .165 & 219,48 & 271,95 & 412,9 \\
\hline Rondônia & 286.525 & 373,30 & 118,13 & 33,9 \\
\hline Roraima & 64.703 & 851,11 & - & - \\
\hline Tocantins & 335.883 & 407,83 & 83,60 & 28,1 \\
\hline Alagoas & 611.163 & 357,34 & 134,09 & 82,0 \\
\hline Bahia & 3.337 .358 & 270,62 & 220,81 & 736,9 \\
\hline Ceará & 1.634 .121 & 284,09 & 207,34 & 338,8 \\
\hline Maranhão & 1.496 .477 & 190,18 & 301,25 & 450,8 \\
\hline Paraíba & 795.642 & 321,24 & 170,19 & 135,4 \\
\hline Pernambuco & 1.593 .714 & 309,34 & 182,09 & 290,2 \\
\hline Piauí & 660.180 & 267,61 & 223,82 & 147,8 \\
\hline Rio Grande do Norte & 582.444 & 346,22 & 145,21 & 84,6 \\
\hline Sergipe & 396.870 & 412,67 & 78,76 & 31,3 \\
\hline Goiás & 1.049 .304 & 369,38 & 122,05 & 128,1 \\
\hline Mato Grosso do Sul & 417.230 & 398,41 & 93,02 & 38,8 \\
\hline Mato Grosso & 515.880 & 387,95 & 103,48 & 53,4 \\
\hline Distrito Federal & 344.873 & 471,14 & 20,29 & 7,0 \\
\hline Espírito Santo & 546.380 & 605,73 & - & - \\
\hline Minas Gerais & 3.657 .558 & 340,60 & 150,83 & 551,7 \\
\hline Rio de Janeiro & 1.875 .522 & 531,30 & - & - \\
\hline São Paulo & 5.631 .226 & 710,89 & - & - \\
\hline Paraná & 1.671 .358 & 394,10 & 97,33 & 162,7 \\
\hline Rio Grande do Sul & 1.603 .671 & 551,06 & - & - \\
\hline Santa Catarina & 905.290 & 505,28 & - & - \\
\hline TOTAL & 32.380.024 & - & - & $3.714,4$ \\
\hline
\end{tabular}

Fontes: Coluna 2 - M EC (Censo Escolar, 1998) e Coluna 3 - Tabela 6.2 (M onlevade \& Ferreira 1997, p. 74). 
A Tabela 3 mostra os percentuais do PN B aplicados no ensino primário, em países selecionados da América Latina, e a Tabela 4 mostra os percentuais para outros países:

Tabela 3

Percentual do PN B: Ensino primário naAmérica Latina (Países selecionados)

\begin{tabular}{lcccccc}
\hline \multicolumn{1}{c}{ País } & $\begin{array}{c}\text { Gastos por } \\
\text { estudante } \\
\text { primário, } \\
\text { \%PNB per } \\
\text { capita } \mathbf{( 1 9 9 6 )}\end{array}$ & $\begin{array}{c}\text { PNB } \\
\text { per capita } \\
\text { (US\$) }\end{array}$ & $\begin{array}{c}\text { Custo do } \\
\text { aluno ao } \\
\text { ano } \\
\text { (1998) }\end{array}$ & $\begin{array}{c}\mathbf{N}^{\mathbf{0}} \text { de alunos } \\
\text { na escola } \\
\text { primária }\end{array}$ & $\begin{array}{c}\text { Volume } \\
\text { total de } \\
\text { recursos } \\
\text { (US\$ }\end{array}$ & $\begin{array}{c}\text { \% do } \\
\text { PNB }\end{array}$ \\
\hline Argentina & 8,3 & 8.970 & 744,51 & 5.153 .256 & 3.837 & 1,18 \\
Chile & 10,1 & 4.810 & 485,81 & 2.241 .536 & 1.089 & 1,53 \\
Colômbia & 10,4 & 2.600 & 270,40 & 2.510 .410 & 679 & 0,64 \\
México & 11,9 & 3.970 & 472,43 & 14.650 .521 & 6.921 & 1,82 \\
Paraguai & 10,9 & 1.760 & 191,84 & 905.813 & 174 & 1,89 \\
Uruguai & 9,3 & 6.180 & 574,74 & 345.573 & 197 & 0,97 \\
Venezuela & 2,2 & 3.500 & 77,00 & 4.262 .221 & 328 & 0,40 \\
Costa Rica & 13,4 & 2.780 & 372,52 & 270.512 & 101 & 1,03 \\
República & 3,3 & 1.770 & 58,41 & 1.492 .596 & 87 & 0,60 \\
Dominicana & & & & & & \\
Equador & 7,6 & 1.530 & 116,28 & 1.888 .172 & 220 & 1,18 \\
El Salvador & 7,0 & 1.850 & 129,50 & 1.191 .052 & 154 & 1,38 \\
Guatemala & 6,1 & 1.640 & 100,04 & 1.544 .709 & 155 & 0,88 \\
Honduras & 9,0 & 730 & 65,70 & 1.008 .181 & 66 & 1,47 \\
\hline
\end{tabular}

Fontes: Coluna 2 - World Development Indicators, Banco M undial (1999) - não existe a informação para o Brasil; Coluna 3 - World D evelopment Report, Banco Mundial (1999/2000); Coluna 5 - U nesco, Statistics: http://unescostat.un... Eprisex19100.asp? ano=1990, 1991, 1992, 1993, 1994, 1995, 1996, 1997/\& nomreg=America; Colunas 4, 6 e 7 - Calculadas.

O s resultados explicitados nas Tabelas 3 e 4 permitem realizar as seguintes observações: 1) o custo do aluno na proposta de Anísio Teixeira no valor de $R \$ 491,43$ que corresponde a US\$417,08* é ainda um valor baixo, se considerarmos países como a Coréia (US\$ 1.498,36), U ruguai (US\$574,74), M éxico (US\$ 472,43), Chile (U S\$485,81) e Argentina (US\$744,51). 0 que dizer então do valor de $\mathrm{R} \$ 315,00$, que corresponde a US\$ 267,35?; 2) em termos de percentuais do PN B, a última coluna indica que a conclusão de Anísio Teixeira, quando afirma

* Considerando a relação entre R \$ e US\$, em 1998, a mesma da relação entre o PIB em R \$ e em US\$, publicados pelo I pea: R\$913.735.044.000,00 e US\$775.501.273.000,30. http:// www.ipeadata.gov.br/ipeaweb/ipeawe.../N serie?SessionI $=1933967395 \&$ SERID $=3197,17 /$ $10 / 2000$ 
que o Brasil pode gastar $2 \%$ do seu PN B no ensino fundamental, estava absolutamente bem situada e continua válida; 3) a China e a Índia são dois países superpopulosos, distorcendo qualquer análise que se faça por número de estudantes, uma vez que as suas dimensões extrapolam qualquer análise que se sustenta em parâmetros da cultura ocidental; ressaltam na Tabela 4 os percentuais aplicados em educação primária pela N oruega $(2,32 \%)$, pela África do Sul $(3,06 \%)$ e pela Suécia $(2,15 \%)$, mostrando uma el evada prioridade para esse nível da educação.

Tabela 4

Percentual do PN B: Ensino primário outros

(Paísesselecionados)

\begin{tabular}{|c|c|c|c|c|c|c|}
\hline País & $\begin{array}{l}\text { Gastos por } \\
\text { estudante } \\
\text { primário, } \\
\text { \% PNB per } \\
\text { capita (1996) }\end{array}$ & $\begin{array}{c}\text { PNB } \\
\text { per capita } \\
\text { (US\$) } \\
(\mathbf{1 9 9 8 )}\end{array}$ & $\begin{array}{c}\text { Custo do } \\
\text { aluno ao } \\
\text { ano (US\$) }\end{array}$ & $\begin{array}{c}\mathbf{N}^{\mathbf{o}} \text { de } \\
\text { alunos na } \\
\text { escola } \\
\text { primária }\end{array}$ & $\begin{array}{l}\text { Volume } \\
\text { total de } \\
\text { recursos } \\
\text { (US\$ } \\
\text { Milhões) }\end{array}$ & $\begin{array}{l}\% \text { do } \\
\text { PNB }\end{array}$ \\
\hline Austrália & 17,4 & 20.300 & $3.532,20$ & 1.855 .789 & 6.555 & 1,72 \\
\hline Áustria & 23,1 & 26.850 & $6.202,35$ & 381.927 & 2.369 & 1,09 \\
\hline Bélgica & 15,1 & 25.380 & $3.832,38$ & 742.796 & 2.847 & 1,10 \\
\hline Bulgária & 31,9 & 1.230 & 392,37 & 431.790 & 169 & 1,67 \\
\hline China & 6,5 & 750 & 48,75 & 139.954 .000 & 6.823 & 1,53 \\
\hline Dinamarca & 25,9 & 33.260 & $8.614,34$ & 336.690 & 2.900 & 1,64 \\
\hline França & 15,8 & 24.940 & $3.940,52$ & 4.004 .704 & 15.782 & 1,08 \\
\hline Índia & 11,6 & 430 & 49,88 & 108.781 .792 & 5.426 & 1,29 \\
\hline Irlanda & 14,4 & 18.340 & $2.640,96$ & 358.830 & 948 & 1,40 \\
\hline Itália & 21,5 & 20.250 & $4.353,75$ & 2.810 .158 & 12.234 & 1,05 \\
\hline Japão & 19,3 & 32.380 & $6.249,34$ & 7.855 .387 & 49.089 & 1,20 \\
\hline Rep. Coréia & 18,8 & 7.970 & $1.498,36$ & 3.810 .932 & 5.710 & 1,54 \\
\hline Nova Zelândia & 17,9 & 14.700 & $2.631,30$ & 357.569 & 941 & 1,69 \\
\hline Noruega & 31,1 & 34.330 & $10.676,63$ & 330.619 & 3.530 & 2,32 \\
\hline África do Sul & 15,5 & 2.880 & 446,40 & 8.159 .430 & 3.642 & 3,06 \\
\hline Espanha & 15,3 & 14.080 & $2.154,24$ & 2.610 .041 & 5.623 & 1,02 \\
\hline Suécia & 27,6 & 25.620 & $7.071,12$ & 690.630 & 4.884 & 2,15 \\
\hline Suíça & 18,8 & 40.080 & $7.535,04$ & 477.643 & 3.599 & 1,26 \\
\hline Reino Unido & 28,8 & 21.400 & $4.023,20$ & 5.328 .219 & 21.436 & 1,70 \\
\hline Estados Unidos & 18,5 & 29.340 & $5.427,90$ & 24.045 .967 & 130.519 & 1,65 \\
\hline
\end{tabular}

Fontes: Coluna 2 - World Development Indicators, Banco M undial (1999); Coluna 3 - World Development Report, Banco M undial (1999/2000), Coluna 5 - U nesco, Statistics, http:// unescostat.un.../E prisex19100.asp?ano = 1990,1991,1992,1993,1994,1995,1996,1997/ \& nomreg=America; Colunas 4, 6 e 7 - Calculadas.

Evidencia-se nessas análises que um país com a riqueza do Brasil, oitavo do mundo na classificação do PN B (Bird, 2000), pode e precisa fixar políticas públicas que procurem ultrapassar o desafio da educação 
para todos, em que a qualidade se expresse pela valorização do professor, dos trabalhadores da área da educação e das condições de trabalho e de vida do cidadão brasileiro.

\section{Conclusões}

U ma comparação esquemática entre as propostas delineadas por Anísio Teixeira e o Fundef mostra que:

\begin{tabular}{|c|c|}
\hline Proposta Anísio Teixeira & Fundef \\
\hline $\begin{array}{l}\text { 1. O custo/aluno/ano seria calculado a } \\
\text { partir da definição do salário do pro- } \\
\text { fessor. }\end{array}$ & $\begin{array}{l}\text { 1. O custo/aluno/ano é calculado a partir } \\
\text { do montante de recursos existente para } \\
\text { aplicação em educação. }\end{array}$ \\
\hline $\begin{array}{l}\text { 2. O volume de recursos a ser aplica- } \\
\text { do: } 20 \% \text { das receitas de impostos de } \\
\text { umnicípios e estados e } 10 \% \text { da receita } \\
\text { de impôstos da União. Se necessário, } \\
\text { novos recursos seriam incorporados, } \\
\text { além da vinculação constitucional. }\end{array}$ & $\begin{array}{l}\text { 2. O volume de recursos a ser aplicado: } \\
\text { 15\% do FPE, do FPM, do ICMS e do } \\
\text { IPI-Exp dos municípios e estados. }\end{array}$ \\
\hline $\begin{array}{l}\text { 3. Para os municípios que não atin- } \\
\text { gissem o custo/aluno/ano com recur- } \\
\text { sos municipais e estaduais, a União } \\
\text { realizaria uma comple-mentação de } \\
\text { recursos. }\end{array}$ & $\begin{array}{l}\text { 3. Para o município que não atingir o } \\
\text { custo/aluno/ano com recursos munici- } \\
\text { pais e estaduais, a União realiza uma } \\
\text { complementação de recursos. }\end{array}$ \\
\hline $\begin{array}{l}\text { 4. 55\% dos recursos deveriam se diri- } \\
\text { gir para o pagamento dos salários dos } \\
\text { professores; } 7 \% \text { para a administração } \\
\text { e serviços; } 13 \% \text { para a biblioteca e } \\
\text { material de ensino; } 15 \% \text { para assistên- } \\
\text { cia, alimentação e saúde e } 10 \% \text { para } \\
\text { prédios e equipamentos. }\end{array}$ & $\begin{array}{l}\text { 4. } 60 \% \text { dos recursos devem ser gastos } \\
\text { com os professores e servidores e } 40 \% \\
\text { dos recursos com a manutenção e de- } \\
\text { senvolvimento da educação. }\end{array}$ \\
\hline 5. Atinge o ensino primário na época. & 5. Atinge o ensino fundamental. \\
\hline $\begin{array}{l}\text { 6. Estabelece a criação de conselhos } \\
\text { com um alto grau de autonomia admi- } \\
\text { nistrativa que gerenciariam os fundos } \\
\text { - nacional, estaduais e municipais. }\end{array}$ & $\begin{array}{l}\text { 6. Estabelece conselhos municipais e } \\
\text { estaduais, acompanhadores/fiscalizado- } \\
\text { res. }\end{array}$ \\
\hline $\begin{array}{l}\text { 7. O número de estudantes em análise } \\
\text { se-riam todos aqueles na faixa etária } \\
\text { de } 7 \text { a } 11 \text { anos, supondo-se educação } \\
\text { primária para todos. }\end{array}$ & $\begin{array}{l}\text { 7. O número de estudantes em análise } \\
\text { são aqueles efetivamente matriculados, } \\
\text { apurados pelo censo escolar. }\end{array}$ \\
\hline 8. O fundo teria caráter permanente. & $\begin{array}{l}\text { 8. O Fundef tem caráter provisório, até } \\
1 \% 01 / 2007 \text {. }\end{array}$ \\
\hline
\end{tabular}


N ota-se, claramente, uma semelhança quanto à metodologia. Entretanto, as diferenças existentes são marcantes. A principal delas está no fato da proposta de Anísio Teixeira calcular o custo/aluno/ano a partir da definição do salário do professor, expressando-se aí uma preocupação real com a qualidade do ensino sem se preocupar inicialmente com 0 volume total de recursos a ser aplicado. Isso não ocorre com o Fundef, que define o custo/aluno/ano a partir de um volume de recursos já pré estabelecido. Portanto, é preciso ressaltar que na proposta Anísio Teixeira não há um limite previamente estabelecido para o volume total de recursos a ser aplicado no ensino primário obrigatório.

Além desse fato principal de diferença, outros chamam a atenção na proposta de Anísio Teixeira: prevê um Conselho de Educação forte e com poderes para controlar a aplicação dos recursos do fundo e não apenas fiscalizar; prega uma educação para todos, quando considera todas as pessoas da faixa etária e não apenas as matriculadas, e estabelece um fundo de caráter permanente, o que permitiria um contínuo aperfeiçoamento e sua definição, aplicação e fiscalização; 0 caráter temporário do Fundef poderá trazer barreiras intransponíveis para aqueles municípios que recebem volumes substanciais de recursos desse fundo, onde fica uma pergunta: como continuar financiando a educação, quando se encerrar o processo de redistribuição entre municípios?

Podemos observar, finalmente, que 0 valor de $R \$ 491,43$, obtido como gasto por aluno ao ano pela abordagem imaginada por Anísio Teixeira, não é muito maior do que os R \$ 423,07 obtidos para 0 ano de 1998, caso o Governo Federal estivesse cumprindo o Art. 60 da Lei $n$ o 9424 no cálculo do valor mínimo anual por aluno, utilizando-se das regras do Fundef. Entretanto, difere substancialmente dos $\mathrm{R} \$ 315,00$ praticados, evidenciando o grau de prioridade com que esse assunto é tratado pelas autoridades governamentais no Brasil, por detrás da imensa campanha publicitária na imprensa nacional, que mostra uma outra realidade à população brasileira.

A utilização desse novo Fundef para o cálculo do custo do aluno ao ano significaria, então, um relativo acréscimo nos recursos atualmente aplicados, ainda insuficiente, compatível com a riqueza nacional, o que proporcionaria o oferecimento de um ensino fundamental obrigatório de melhor qualidade e uma real valorização do magistério, além da retórica presente no nome do fundo: Fundo de $M$ anutenção e D esenvolvimento do Ensino Fundamental e de Valorização do M agistério.

Recebido para publicação em dezembro de 2000. 


\begin{abstract}
A new Fundef?
Anísio TeIXeIRA's IDEAS

ABST RACT: Professor Anísio Teixeira in the sixties, concerned with the financing of the education, presented a proposal of how to define and implement a fund to guaranteepermanent resourcesfor theprimary teaching. In his methodological aspects, the fund now created by the Government, called "Fund for the M aintenance and D evelopment of the Fundamental Teaching and of Valorization of the Teaching (Fundef)", resembles the original proposal presented by AnísioTeixerra. Thereexist, however, important and fundamental differences, due to the fact that in Teixeira's proposal the total volume of resources is calculated from the establishment of the teacher's wage. In this study it is presented the similarities and differences between the two Funds and a simulation is performed, resulting in what one could call "A new Fundef", based on Teixeira's ideas. As a result it is obtained values perfectly viable to be financed by an economy of the dimension of the Brazilian's as pointed out by in the study presented by Anísio Teixeira in the book Educação é um direito.
\end{abstract}

Key words: Financing; Fundamental teaching; Fund; Fundef.

\title{
Referências bibliográficas
}

BIRD. World Development Report 1999/2000. Banco M undial. http:// www.worldbank.org/wdr/2000/pdfs/engtablel.pdf (pesquisa feita na Internet em 17/10/2000).

DAVIES, N . 0 Fundef e 0 orçamento da educação: D esvendando a caixa preta. N iterói: Xamã, 1998.

DIEESE. Salário M ínimo: Pouca comemoração para o 1o de maio. 2000. http://www. dieese.org.br/esp/salmin99.html (pesquisa feita na Internet em 31/08/2000).

IPEA. Exibição de Séries, em IPEAD ATA, Brasília-DF, 2000. http:// www.ipeadata.gov.br/ipeaweb/ipe.../N serie? Sessionl D = 19339 $67395 \&$ SERID =3599 (pesquisa feita na Internet em 17/10/2000).

LEI 9424. Dispõe sobre o Fundo de M anutenção e D esenvolvimento do Ensino Fundamental e de Valorização do M agistério, na forma prevista no art. 60 do Ato das Disposições Transitórias, e dá outras providências. Art. 6으, Braślia (DF), 1996.

MEC. Fundef: Balanço do primeiro ano do Fundef. Brasília: MEC, 1999, p. 19. 
MONLEVADE, J. e FERREIRA, E. O Fundef e seus pecados capitais. Ceilândia (DF): I déia Editora, 1997.

TEIXEIRA, Anísio. A educação e a crise brasileira. São Paulo: Companhia Editora N acional, 1956.

Bases preliminares para o plano de educação referente ao Fundo N acional de Ensino Primário. Revista Brasileira de Estudos Pedagógicos no 88, vol. 38, Rio de Janeiro, out./dez. 1962, p. 97-107.

Educação é um direito. São Paulo: Companhia Editora N acional, 1968. 